\title{
Fault Analysis of Brake Oil and Coolant Filling Machine
}

\author{
Mohan Mali ${ }^{1}$ H. P. Khairnar ${ }^{2}$ \\ ${ }^{1}$ PG Student, Department of mechanical engineering, VJTI, Mumbai, India \\ ${ }^{2}$ Associate Professor, Department of mechanical engineering, VJTI, Mumbai, India
}

\begin{abstract}
The performance and quality of components such as power steering, radiator, brakes, steering, clutch, engine, gears and air conditioner is mainly determined by the exact filling with fluids. The fluid pressure, concentration and physical properties are very important from the working point of view. In order to ensure correct working of such fluid filling machines, it is necessary to eliminate their problems causing huge assembly line downtime. The paper describes few suggestions to eliminate the problems occurring in the brake oil and coolant filling machine used for filling the fluids in the cars. The continuous observation and thorough analysis have resulted into the data described here.
\end{abstract}

Keywords: brake oil, coolant, filling machine

\section{Introduction}

Brake spongy is the soft feeling of brake pedal that means brake pedal travel before any action takes place in brake system. It should be between 1 to $3 \mathrm{~mm}$, if brake pedal free play is greater than $3 \mathrm{~mm}$ it causes brake spongy. Brake spongy is related to forces in braking system, brake system components, brake fluid filling equipment. ${ }^{[2]}$

This equipment is designed to automatically fill vehicle air conditioning and brake circuits. The circuits are filled using adapter(s). The adapters (or filling heads) are the main tools used by the operator. The system components are as follows:

- A Main Control Panel (MCP) including PLC

- An HMI operating panel

- One Fixed Unit electrical panels, including relays, protection devices, etc.

- Two hydraulic/pneumatic base units one for the Air Conditioning process (AC), one for the Brake process (BK)

One mobile filling unit including the Air Conditioning hydraulic, the Brake hydraulic and the electrical parts, the fill adapters and ABS connector.

The mobile unit is equipped with a tractor drive unit to follow the vehicle movement on the line.

The filling cycles are automatic. The operator must be present at the start and end of the cycle.

The AC/Brake filling equipment is divided into (4) major subsystems as follows:

- One Main Control Panel (MCP).

- This panel is connected to the HMI of the equipment that is installed on a separated support.

- One Electrical Fixed Unit Panel

- Two Hydraulic / Pneumatic Base Units (one for AC and one for BK)

- One Mobile Unit for on line fluid dispensing

\section{Sequence of Operation}

- Pressurization (Only for Coolant Filling):

Filling the complete circuit with pressurized air to check any leakage. As the coolant circuit in the car is spread over a wide area and having long pipes, it is necessary to check the leakage in the circuit by filling pressurized air into it.

- Stabilization (Only for Coolant Filling):

Waiting till the pressure in the circuit stabilize. Some time is allowed to stabilize the pressure in the circuit

- Pressure test (Only for Coolant Filling):

Checking the pressure of air inside the circuit

The machine follows the above process as a procedure, during which the vacuum test is a process where the machine test the whole system for vacuum. The company follows a standard of maintaining a vacuum pressure of 1.1 to 1.6 torr. Then the machine tests the system for any leak. The leak is of two type's small leak and large leak. Normally a small leak occurs when the joints are not being torque checked and a large leak occurs when the mountings are improper. Then it fills the oil for the required quantity under pressure. This is the process in which the machine checks the oil level and top up is done if needed or else the extra amount of oil filled is sucked out and brought to the required level. Then alarm sounds which signifies the completion of the whole process. The whole process time comes around 65 seconds and the car moves to the next section. ${ }^{[1]}$

- Vacuuming(Vacuum1 and vacuum2):

Removing the air from the circuit with the dirt, dust etc. in order to avoid spongy effect of brake

- High Pressure Filling:

Filling the fluid with high pressure so that it will reach to every part of the circuit

- Low Pressure Filling:

Filling the fluid with low pressure so that it will not overflow

- Levelling:

Adjusting the final required level of fluid in the tank 
International Journal of Science and Research (IJSR)

ISSN (Online): 2319-7064

Index Copernicus Value (2013): 6.14 | Impact Factor (2015): 6.391

\section{Observations}

Table 1: Coolant filling readings

\begin{tabular}{|c|c|c|c|c|}
\hline Operation & $\begin{array}{c}\text { Pressure } \\
\text { (Bar) }\end{array}$ & $\begin{array}{c}\text { Pressure } \\
\text { (Bar) }\end{array}$ & Time & Time \\
\hline Vehicle Type & $\begin{array}{c}\text { RHD } \\
\text { (India) }\end{array}$ & $\begin{array}{c}\text { LHD } \\
\text { (Export) }\end{array}$ & $\begin{array}{c}\text { RHD } \\
\text { (India) }\end{array}$ & $\begin{array}{c}\text { LHD } \\
\text { (Export) }\end{array}$ \\
\hline Pressurization & 1.45 & 1.49 & 10 & 10 \\
\hline Stabilization & 1.44 & 1.48 & 5 & 5 \\
\hline Pressure Test & 1.43 & 1.48 & 5 & 5 \\
\hline PreVacuum & $3.7^{*} 10^{\wedge}-3$ & $8^{*} 10^{\wedge}-3$ & 38 & 29 \\
\hline Vacuum Check & $9.4^{*} 10^{\wedge}-3$ & $14.6^{*} 10^{\wedge}-3$ & 5 & 5 \\
\hline 2nd Vacuum & $3.4^{*} 10^{\wedge}-3$ & $7.8^{*} 10^{\wedge}-3$ & 5 & 3 \\
\hline final pressure & 1.1 & 1.1 & -- & -- \\
\hline
\end{tabular}

Following are some of the faults observed in filling machines

- Mass under target: It shows that the mass of the fluid filled in the vehicle tank is less than the required quantity

Possible causes

1) Fluid meter malfunctioning

2) Insufficient fluid in the supply tank

3) Filling time set is lesser than required

Table 2: Brake Oil filling readings

\begin{tabular}{|c|c|c|}
\hline Operation & $\begin{array}{c}\text { Pressure (Bar) } \\
\text { RHD (India)\&LHD } \\
\text { (Export) }\end{array}$ & $\begin{array}{c}\text { Time (sec) } \\
\text { RHD (India)\&LHD } \\
\text { (Export) }\end{array}$ \\
\hline Prevacuum & $0.3^{*} 10^{\wedge}-3$ & 37 \\
\hline Vacuum Check & $1.7^{*} 10^{\wedge}-3$ & 7 \\
\hline $2^{\text {nd }}$ Vacuum & $0.3^{*} 10^{\wedge}-3$ & 3 \\
\hline Final Pressure & 4.5 & -- \\
\hline
\end{tabular}

\section{- Mass over target}

It shows that the mass of the fluid filled in the vehicle tank is more than the required quantity

Possible causes

1. Fluid meter malfunctioning

2. Filling time set is more than required

\section{- Density fault}

This shows that the density value of the water-glycol mixture is out of the required range.

Possible causes

1. Improper quantity of water and glycol mixed

\section{- ABS actuation Fault}

It indicates that the ABS system is not actuated which is required for brake fluid filling in vehicles provided with ABS

Possible causes

1. Communication error between electric supply and ABS socket

2. Ignition key not switched to ON position

\section{Problem Elimination}

\section{- Mass under target}

It shows that the mass of the fluid filled in the vehicle tank is less than the required quantity

Causes

1) Fluid meter malfunctioning
Action Taken-: Fluid meter calibration done

2) Insufficient fluid in the supply tank

Action Taken-: Fluid suction hose fixed to such a position that it will be always covered with sufficient amount of fluid

3) Filling time set is lesser than required

Action Taken-: Filling time has set to a correct value

\section{- Mass over target}

It shows that the mass of the fluid filled in the vehicle tank is more than the required quantity

Causes:

1) Fluid meter malfunctioning

Action Taken-: Fluid meter calibration done

2) Filling time set is more than required

Action Taken-: Filling time has set to a correct value

\section{- Density fault:}

This shows that the density value of the water-glycol mixture is out of the required range.

Causes:

Improper quantity of water and glycol mixed

Action Taken-: The flow counter calibration done

\section{- ABS actuation Fault:}

It indicates that the ABS system is not actuated which is required for brake fluid filling in vehicles provided with ABS

\section{Causes}

1) Communication error between electric supply and ABS socket

Action Taken -: Connection cable checked for its proper functioning and replaced

2) Ignition key not switched to ON position Action Taken: - Ignition key switched to ON position

\section{Conclusion}

The faults occurring in the brake and coolant oil filling machine can be easily eliminated by thorough analysis and continuous observation of the process. The elimination of small faults occurring in the coolant and brake oil filling machine can lead to reduction of the vehicle assembly line downtime.

\section{References}

[1] R. Anbazhagan, S. Vanangamudi, C. Thamotharan, S. Prabhakar and C. Coomarasamy, "4m-Analyses on the Brake Oil Filling Machine"Middle-East Journal of Scientific Research 20 (11): 1425-1430, 2014 ISSN 1990-9233, IDOSI Publications, 2014

[2] M. Chethan, Dr. D N Shivappa and Santosh S Navada, “ Analysis Of Brake Spongy Defect In Passenger Vehicle And Developing The Counter Measures - QI Case Study" National Conference on Trends and Advances in Mechanical Engineering TAME-2012 OCT 19-20, 2012 Department of Mechanical Engineering, YMCA University of Science and Technology, Faridabad 


\section{Author Profile}

Mohan Mali is a post graduate student in mechanical engineering department, VJTI, Mumbai. He has completed B.E. in Mechanical Engineering from University of Pune.

Volume 5 Issue 6, June 2016 www.ijsr.net 